\title{
Interneuron Simplification and Loss of Structural Plasticity As Markers of Aging-Related Functional Decline
}

\author{
Ronen Eavri, ${ }^{1}$-Jason Shepherd, ${ }^{1}$ CChristina A. Welsh, ${ }^{1,2}$ Genevieve H. Flanders, ${ }^{1}{ }^{-}$Mark F. Bear, ${ }^{1,3}$ and $\odot$ Elly Nedivi ${ }^{1,2,3}$ \\ ${ }^{1}$ Picower Institute for Learning and Memory, Departments of ${ }^{2}$ Biology, and ${ }^{3}$ Brain and Cognitive Sciences, Massachusetts Institute of Technology, \\ Cambridge, Massachusetts 02139
}

Changes in excitatory neuron and synapse structure have been recognized as a potential physical source of age-related cognitive decline. Despite the importance of inhibition to brain plasticity, little is known regarding aging-associated changes to inhibitory neurons. Here we test for age-related cellular and circuit changes to inhibitory neurons of mouse visual cortex. We find no substantial difference in inhibitory neuron number, inhibitory neuronal subtypes, or synapse numbers within the cerebral cortex of aged mice compared with younger adults. However, when comparing cortical interneuron morphological parameters, we find differences in complexity, suggesting that arbors are simplified in aged mice. In vivo two-photon microscopy has previously shown that in contrast to pyramidal neurons, inhibitory interneurons retain a capacity for dendritic remodeling in the adult. We find that this capacity diminishes with age and is accompanied by a shift in dynamics from balanced branch additions and retractions to progressive prevalence of retractions, culminating in a dendritic arbor that is both simpler and more stable. Recording of visually evoked potentials shows that aging-related interneuron dendritic arbor simplification and reduced dynamics go hand in hand with loss of induced stimulus-selective response potentiation (SRP), a paradigm for adult visual cortical plasticity. Chronic treatment with the antidepressant fluoxetine reversed deficits in interneuron structural dynamics and restored SRP in aged animals. Our results support a structural basis for age-related impairments in sensory perception, and suggest that declines in inhibitory neuron structural plasticity during aging contribute to reduced functional plasticity.

Key words: aging; fluoxetine; inhibitory neurons; mice; two-photon microscopy; visually evoked potential

Significance Statement

Structural alterations in neuronal morphology and synaptic connections have been proposed as a potential physical basis for age-related decline in cognitive function. Little is known regarding aging-associated changes to inhibitory neurons, despite the importance of inhibitory circuitry to adult cortical plasticity and the reorganization of cortical maps. Here we show that brain aging goes hand in hand with progressive structural simplification and reduced plasticity of inhibitory neurons, and a parallel decline in sensory map plasticity. Fluoxetine treatment can attenuate the concurrent age-related declines in interneuron structural and functional plasticity, suggesting it could provide an important therapeutic approach for mitigating sensory and cognitive deficits associated with aging.

\section{Introduction}

A large fraction of persons older than 85 years have significant cognitive impairment and dementia (Gallo and Lebowitz, 1999;

\footnotetext{
Received March 22, 2018; revised Aug. 7, 2018; accepted Aug. 7, 2018.

Author contributions: R.E., J.S., C.A.W., G.H.F., and M.B. edited the paper; R.E., J.S., M.B., and E.N. designed research; R.E., J.S., C.A.W., and G.H.F. performed research; R.E., J.S., C.A.W., G.H.F., and E.N. analyzed data; E.N. wrote the paper.

This work was supported by National Eye Institute Grants R01EY01756 (E.N.), R01EY025437 (E.N.), and R01EY023037 (M.B.), a Julie Martin Mid-Career Award in Aging Research to E.N. from the AFAR and Ellison Medical Foundation, a Machiah Foundation fellowship to R.E., and K99-NS076364 from NINDS to J.S. We thank Jae Won Cha and Peter So for two-photon microscopy support, and members of the Nedivi laboratory for critical reading of the paper.

The authors declare no competing financial interests.

Correspondence should be addressed to Elly Nedivi, Massachusetts Institute of Technology, 43 Vassar Street, Cambridge, MA 02139. E-mail: nedivi@mit.edu.

J. Shepherd's present address: Department of Neurobiology and Anatomy, University of Utah, Salt Lake City, UT 84112
}

Hebert et al., 2013; Wu et al., 2016). The decline in cognitive abilities begins much earlier (for review, see Zec, 1995), and although in many cases it is related to dementias such as Alzheimer's Disease, a decline in cognitive capacity has also been associated with normal aging (Petersen et al., 2018). Most common are declines in memory, performance of language, and executive function tasks (for review, see Hof and Morrison, 2004; Kirova et al., 2015), as well as sensory perception (Kalisch et al., 2009; Hickmott and Dinse, 2013; for review, see Andersen, 2012).

Despite common belief, loss of neurons due to cell death is quite limited during normal aging and unlikely to account for age-related functional impairments (for review, see Peters et al., 1998). Rather, it seems that structural alterations in neuronal 
morphology and synaptic connections are features most consistently correlated with brain age, and may be considered as the potential physical basis for the age-related decline in cognitive function (for review, see Morrison and Baxter, 2012). Multiple cellular changes have been reported in the aging brain. These include reductions in the size of dendritic and axonal arbors, in spine numbers, and in synaptic efficacy (Jacobs and Scheibel, 1993; Masliah et al., 1993; Kawaguchi et al., 1995; Anderson and Rutledge, 1996; Ou et al., 1997; Shankar et al., 1998; Grill and Riddle, 2002; Bloss et al., 2011; Mostany et al., 2013). Although a decrease in adult neurogenesis has also been noted, this is mainly relevant to the hippocampus (Kuhn et al., 1996).

Studies of structural alterations related to brain aging have mostly focused on the excitatory network. Recently, chronic twophoton in vivo imaging has revealed that in contrast to the stability of dendritic arbors of pyramidal neurons in the adult brain, inhibitory interneurons in cortical layer (L)2/3 retain the capacity to remodel in the adult on a day-to-day basis (Lee et al., 2006, 2008; Chen et al., 2011a; Chen and Nedivi, 2013). Furthermore, it is increasingly evident that inhibition plays a key role in cognitive abilities as well as experience-dependent plasticity (Dan and Poo, 2004; Fernandez and Garner, 2007). Inhibitory circuit development is crucial for both the onset and closure of developmental critical periods, and reducing inhibition pharmacologically can restore a juvenile state of plasticity to the adult neocortex (for review, see Hensch, 2004, 2005; Sale et al., 2010). In particular, the widely used antidepressant drug fluoxetine, which reduces intracortical inhibition, has been shown to promote interneuron branch remodeling in the adult mouse visual cortex (Chen et al., 2011b), and restore juvenile levels of ocular dominance plasticity (Maya Vetencourt et al., 2008). Despite the importance of the inhibitory circuitry to adult cortical plasticity and the reorganization of cortical maps (Jacobs and Donoghue, 1991; Jones, 1993), little is known regarding aging-associated changes to inhibitory neurons.

Here we show that morphological plasticity mechanisms that enable inhibitory cell remodeling in L2/3 of the adult mouse visual cortex are lost during the aging process, that the loss is gradual, and already begins in young adults. We characterize the time course of the decline in inhibitory circuit structural plasticity and show that it is congruent with loss of functional synaptic plasticity. Further, we show that use of the antidepressant fluoxetine has a beneficial effect, preventing declines in both structural and functional manifestations of inhibitory circuit aging, and that this effect is dependent on time of onset and length of treatment.

\section{Materials and Methods}

All animal work was approved by the Massachusetts Institute of Technology Committee on Animal Care and conforms to National Institutes of Health guidelines for the use and care of vertebrate animals.

Surgical procedures and fluoxetine administration. To allow long-term visualization of in vivo neuronal morphology, cranial windows were implanted bilaterally over the visual cortices of adult male thy1-GFP-S mice as previously described (Lee et al., 2008) $21 \mathrm{~d}$ before they reached 3, 6, 9, 12 , or 18 months of age, with the following modifications. Windows were $4 \mathrm{~mm}$, and older animals usually needed additional dosing of anesthetics compared with previous studies in young adults. Animals were housed singly after window insertion. Sulfamethoxazole (SMX; $1 \mathrm{mg} / \mathrm{ml}$ ) and trimethoprim (TMP; $0.2 \mathrm{mg} / \mathrm{ml}$ ) were chronically administered in the drinking water through the final imaging session to maintain optical clarity of implanted windows. For animals subjected to fluoxetine treatment, fluoxetine-hydrochloride $(160 \mathrm{mg} / \mathrm{L})$ was chronically administered in the drinking water with SMX-TMP supplemented in the food pellet ( $6 \mathrm{mg}$ and $1 \mathrm{mg}$, respectively, per pellet; Bio-Serv). SMX-TMZ dosage was approximately equivalent for both administration routes, based on measured consumption of 5-13 $\mathrm{ml}$ of water, and $1-3$ pellets per day. Because animals were not water or food restricted, consumption per day varied for individual animals and between animals, within the same range of SMX-TMP regardless of administration route. Water usage at $\sim 5-13 \mathrm{ml}$ per day is sufficient to maintain fluoxetine serum levels at $\sim 200 \mathrm{ng} / \mathrm{ml}$, well above the recommended therapeutic range of $15-55 \mathrm{ng} / \mathrm{ml}$ for humans (according to fluoxetine drug label prescribing information).

Two-photon imaging. Starting 3 weeks after cranial window surgery, mice were anesthetized with $1.25 \%$ avertin $(7.5 \mathrm{ml} / \mathrm{kg}$, i.p.). Anesthesia was monitored by breathing rate and foot pinch reflex, with additional doses administered as needed. In vivo two-photon imaging was performed using a custom-built microscope modified for in vivo imaging with a stereotaxic restraint affixed to a stage insert and custom acquisition software. The light source for two-photon excitation was a commercial Mai Tai HP Ti:Sapphire laser (Spectra-Physics) pumped by a $14 \mathrm{~W}$ solid-state laser delivering $100 \mathrm{fs}$ pulses at a rate of $80 \mathrm{MHz}$ with the power delivered to the objective ranging from $\sim 37-50 \mathrm{~mW}$ depending on imaging depth. $Z$-resolution was obtained with a piezo actuator positioning system (Piezosystem Jena) mounted to the objective. The excitation wavelength was set to $950 \mathrm{~nm}$, with the excitation signal passing through a $20 \times / 1.0$ NA water-immersion objective (Plan-Apochromat, Zeiss) and collected after a barrier filter by a photomultiplier tube. Given the sparse GFP expression in the thy1-GFP-S line, typically only one cell was imaged per animal. Interneurons were identified based on their complex, local dendritic arborization, lack of apical dendrite, small diameter dendritic processes, and absence or sparseness of dendritic spines. While there has been some debate regarding an inflammatory response in the cranial window preparation affecting dendritic spine dynamics (Xu et al., 2007), we have previously shown that cranial window insertion and imaging by our protocol does not affect dendritic arbor or spine dynamics directly or through recruitment of an immune response (Lee et al., 2008).

Imaging data analysis. Using MATLAB (MathWorks) and ImageJ (National Institutes of Health), 16-bit two-photon raw scanner data were converted into an 8-bit image $z$-stack. For each cell, 4 -D $(x, y, z$, and $t)$ stacks were manually traced in Neurolucida (MBF Biosciences) and analyzed blind to age or treatment. Every imaged cell was independently reconstructed at each time point and branch tip length measurements were obtained for all branches. The only branch tips (segments of dendrite from the last branch point to the branch terminal ending) included in the analysis were those that could be confidently identified across all imaging sessions in relation to local landmarks, did not extend beyond the imaging volume, and were not obscured by blood vessels. The branch length refers to the distance from the last branch point to the tip. For unbiased identification of dynamic branch tips, a Fano factor (FF) value was calculated based on branch tip length measurements obtained from Neurolucida across all imaging sessions. The FF is defined as the variance in the measured length of an individual branch tip across all imaging sessions, divided by the mean length of that branch tip $\left(\mathrm{FF}=\frac{S^{2}}{\bar{X}}\right.$, where $\left.S^{2}=\frac{\Sigma(X-\bar{X})^{2}}{n-1}\right)$. The FF has been previously shown to represent the best nonbiased indicator of branch tip dynamics compared with other methods of analysis and robustly identifies small branch tip changes while accounting for measurement variability during imaging or manual reconstructions (Lee et al., 2008). The reason that in practice the FF best represents the population of dynamic branch tips likely hinges on the fact that a majority of remodeling occurs on relatively short branch tips. Normalizing by the average branch tip length helps identify shorter branch tips that are dynamic and minimizes the effects of measurement variability/error in longer branch tips. Branch tips with $\mathrm{FF}>1.09$, representing the $1.5 \times$ interquartile range above the upper quartile of the sample population, were confirmed as dynamic by visual examination. A mean FF $>0.35$ across all monitored branch tips of individual L2/3 interneurons was previously determined to represent a dynamic cell (Lee et al., 2008). To determine the percentage of extending and retracting branches, the FF was calculated for each branch tip for each two consecutive imaging sessions. A branch tip changing sufficiently between two imaging sessions for FF $>1.09$ was considered a 
dynamic event. Thus, each branch tip could produce several dynamic events. Each dynamic event was scored as a retraction or as an extension. The percentage of extensions versus retractions was then calculated across the entire population of cells for each age.

Immunohistochemistry. Cellular immunohistochemistry was performed as in (Chattopadhyaya et al., 2004), with modifications as follows: Animals were perfused transcardially with PBS containing heparin (1:1000; Sigma-Aldrich), followed by $4 \%$ paraformaldehyde (PFA). Brains were then removed and postfixed overnight in 4\% PFA. Fifty micrometer sections containing the visual cortex were cut using a vibratome (Leica VT1000S) and blocked for $2 \mathrm{~h}$ in solution containing $10 \%$ normal goat serum (NGS) or $10 \%$ fetal calf serum (FCS) and $1 \%$ Triton X-100. Sections were incubated $24-60 \mathrm{~h}$ at $4^{\circ} \mathrm{C}$ in a solution containing PBS, $5 \%$ NGS or FCS, and $0.1 \%$ Triton X-100 and either guinea pig $\alpha$-GABA (1:2000; Millipore, AB175) or rabbit $\alpha$-GABA (1: 2000; Sigma-Aldrich, A2052) with one of the following primary antibodies: rabbit $\alpha$-parvalbumin (PV; 1:5000; Swant, PV28), rabbit $\alpha$-vasoactive intestinal peptide (1:2000; Immunostar, 20077), goat $\alpha$-calretinin (1:1000; Swant, CG1), or rat $\alpha$-somatostatin (1:200; Millipore, MAB354). Sections were washed three times in PBS then incubated with a secondary antibody solution containing PBS, $5 \%$ NGS or FCS, and 0.1\% Triton X-100 and the appropriate AlexaFluor 555- and AlexaFluor 647-conjugated secondary antibody (1:400). Sections were then washed three times in PBS, where 4,6-diamino-2-phenylindole (DAPI; SigmaAldrich) was included in the first wash, then mounted for visualization in Fluoromount-G (Southern Biotech). Images were collected on an upright epi-fluorescent scope (Nikon) using a $10 \times$ objective/N.A. 0.3 (Nikon). For each section, images of the same area and focal plane of the visual cortex were taken using separate filters to identify DAPI (blue), GFP (green), AlexaFluor 555 (red), and AlexaFluor 647 (far red) labeled cells. Image (NIH) was used for identification and quantification of double- or triple-labeled cells within each layer. Quantifications were done by layer as defined by DAPI staining. Because layer size is not uniform across sections, a rectangle was defined encompassing the maximum area for each layer within a section and all the GABA-positive cells were counted, whether costained for a second marker or not.

For synapse density analysis, immunohistochemistry was performed as described above except sections were cut at $40 \mu \mathrm{m}$ (for excitatory synapses) or $50 \mu \mathrm{m}$ (for inhibitory synapses) and primary incubation was performed overnight. Primary antibodies were guinea pig $\alpha$ VGLUT1 (1:1000; Synaptic Systems), rat $\alpha$-GFP (Nacalai Tesque), rabbit $\alpha$-GABA (Sigma-Aldrich), and rabbit $\alpha$-VGAT (1:1000; Synaptic Systems).

Images were obtained with a $z$-spacing of $0.5 \mu \mathrm{m}$ from layer $2 / 3$ of the visual cortex with a FluoView IX70 laser-scanning confocal microscope (Olympus), using a $60 \times$ UPlanApo water-immersion objective (Olympus) and the FluoView software (Olympus). Excitatory and inhibitory cells were identified based on morphology and immunohistochemistry. Neurons were defined as excitatory if they possessed a triangular cell body, one clear apical dendrite, and spiny dendrites. GABA-expressing neurons were considered inhibitory.

Images were analyzed using ImageJ (National Institute of Health). Synapses were counted if they consisted of puncta (multiple contiguous pixels brighter than background) that touched, or overlapped with, clearly visible dendrites extending from the cell of interest. To separate actual synapses from background noise, only points that were visible in at least two subsequent focal planes were included in the analysis. Dendrites were traced in Neurolucida (MBF Bioscience) software, and their lengths obtained from Neurolucida Explorer (MBF Bioscience).

Visually evoked potential recordings. For electrode implantation, thy1GFP-S mice were anesthetized with an intraperitoneal injection of 50 $\mathrm{mg} / \mathrm{kg}$ ketamine and $10 \mathrm{mg} / \mathrm{kg}$ xylazine, and a local anesthetic of $1 \%$ lidocaine hydrochloride $(1 \mathrm{mg} / \mathrm{ml})$ was injected over the scalp. For purposes of head fixation, a post was fixed to the skull just anterior to bregma using cyanoacrylate and dental cement. Two small $(<0.5 \mathrm{~mm})$ burr holes were made in the skull overlying the binocular visual cortex ( $3 \mathrm{~mm}$ lateral of lambda) and tungsten microelectrodes (FHC) were inserted $450 \mu \mathrm{m}$ below the cortical surface along the dorsal-ventral stereotaxic axis, positioning the electrode tip at the depth yielding the maximal field potential, which has been shown by current-source density analysis to be sensitive to changes in current sinks in layer $2 / 3$ and 4 (Cooke et al., 2015). Reference electrodes were placed bilaterally in prefrontal cortex. Electrodes were secured in place using cyanoacrylate and the entire exposure was covered with dental cement. Mice were monitored postoperatively for signs of infection or discomfort and were allowed at least $24 \mathrm{~h}$ recovery before habituation to the restraint apparatus.

Visually evoked potential (VEP) recordings were conducted in awake mice. Mice were habituated to the restraint apparatus before the first recording session, and were alert during recording. Visual stimuli were presented to left and right eyes randomly. A total of 100-400 stimuli were presented per condition. VEP amplitude was quantified by measuring trough to peak response amplitude, as described previously (Frenkel and Bear, 2004; Frenkel et al., 2006).

Visual stimuli consisted of full-field sine wave gratings of varying contrast $(0-100 \%)$ generated by a VSG2/2 card (Cambridge Research System) and presented on a computer monitor suitably linearized by $\gamma$-correction. VEPs were elicited by horizontal, vertical, or oblique $\left(45^{\circ}\right.$ or $135^{\circ}$ ) bars. The display was positioned $20 \mathrm{~cm}$ in front of the mouse and centered on the midline, thereby occupying $92^{\circ} \times 66^{\circ}$ of the visual field. Mean luminance, determined by a photodiode placed in front of the computer screen, was $27 \mathrm{~cd} \cdot \mathrm{m}^{-2}$.

Experimental design and statistical analysis. Only male mice were used for this study. The cells used for the 3 month time points in Figures 1D, 2, and 4 were previously described by Chen et al. (2011b) and Lee et al. (2008), and some of the 3 month time points in Figure $3 C$ were previously published by Chen et al. (2011b). The 3, 6, and 9 month data points used in Figure $4 B$ were also used in Figure $1 D$. Cells from all ages, including previously analyzed cells, were independently analyzed blind to age and treatment by two people. For Figures 3,5 , and 6, each $n$ corresponds to one animal (Fig. $3 A$ : 3 months, $n=3-5$; 24 months, $n=3-6$; $B$ : GABA-positive cells, $n=3$; thyl-GFP-nonpyramidal cells, $n=6-8$; $C-E: n=7-9$ for all conditions; $5: 3$ months, $n=5 ; 6$ months, $n=10$; 9 months, $n=5$; 6A: treated, $n=6$; untreated, $n=10$. 6B: 9 months untreated, $n=5 ; 9$ months with 3 month treatment, $n=11 ; 9$ months with 6 month treatment, $n=5$ ). For Figures 1,2 , and 4 , each $n$ corresponds to one cell, with only one cell imaged per animal (Fig. 1:3 months, $n=16$; 6 months, $n=14$; 9 months, $n=10 ; 12$ months, $n=8$; 18 months, $n=11 ; 2: 3$ months, $n=51 ; 12$ months, $n=38$ ). Figure. 2 made use of a larger dataset, because morphological analysis only requires a single time point per cell, and could include cells imaged only once, and the first session of control cells for experiments with other imaging time lines (Fig. 4: $n=$ same as for 1 , and in addition $n=8$ for 6 months with 3 month treatment, $n=8$ for 9 months with 3 month treatment, $n=6$ for 9 months with 6 months treatment).

Statistical significance was primarily evaluated using Student's $t$ test (unpaired for across-animal comparison, paired for within-animal comparison) and MANOVAs (repeated-measures for within-animal comparisons) with posttests for multiple comparisons. Differences in variances were evaluated using the Brown-Forsythe test. Fractions were compared using Fisher's exact test. Distributions were compared using the Kolmogorov-Smirnov test. See Results and figure legends for specifics on statistical tests for each experiment. For Figures 1 and 4, the large within group variance in cell dynamics per animal at some ages, precluded use of tests that assume equal variance. We therefore used a bootstrap approach to test if the mean of two conditions was different: For each bootstrap repeat, we resampled the data in each condition with replacement and computed the difference of the means of the resampled datasets. We performed $10^{6}$ repeats. If the majority of repeats showed a difference $>0$, we report as $p$ values the fraction $<0$; if the majority of repeats showed a difference $<0$ the $p$ value is the fraction $>0$. Statistical analysis was performed with MATLAB (MathWorks) and GraphPad Prism v7 for Mac.

\section{Results}

Interneuron dendritic arbor remodeling progressively decreases with age

In vivo imaging studies using thy 1-GFP-S transgenic mice have revealed that dendrites of inhibitory interneurons in the adult 
A
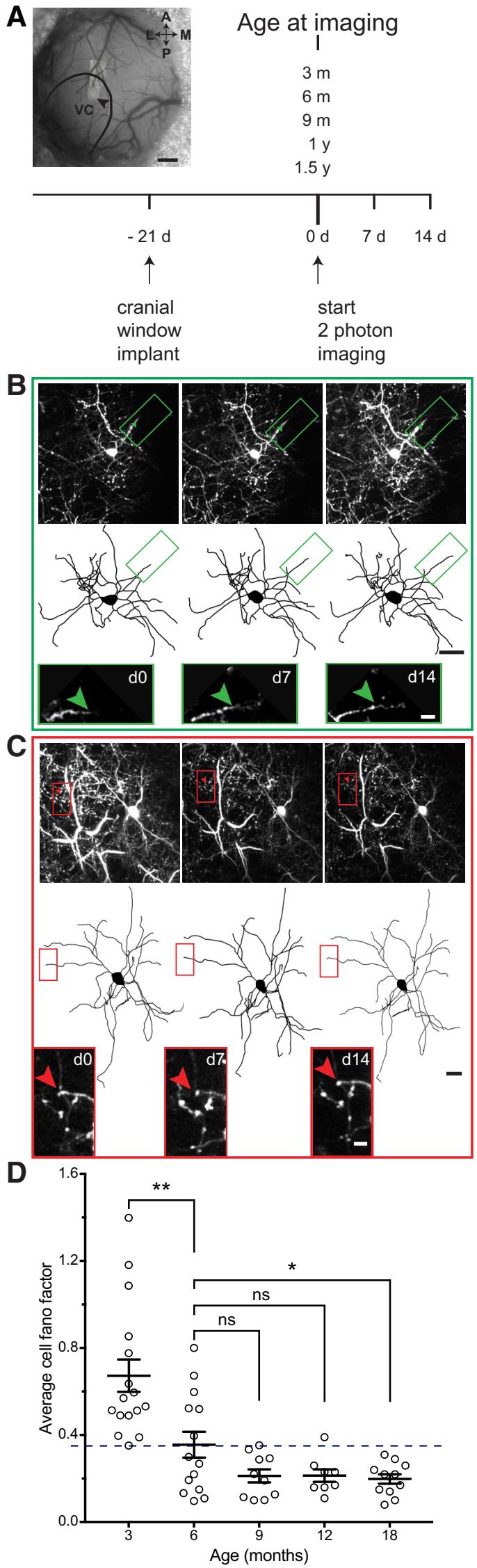

Figure 1. Chronic two-photon in vivo imaging of dendritic branch tip dynamics in superficial L2/3 cortical interneurons. A, Left, A maximum z-projection (MZP) of chronically imaged interneuron (black arrow) superimposed over blood vessel map with primary visual cortex (VC)
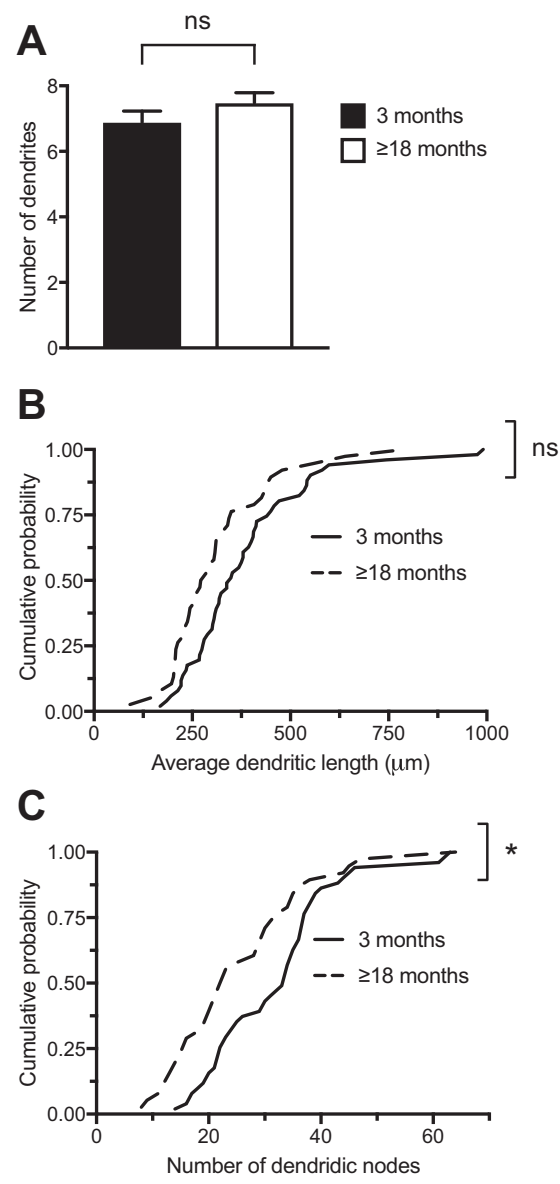

Figure 2. Interneuron dendritic arbors simplify with age. $A$, The number of primary dendrites of V1 interneurons does not change between 3 and 18 months ( $p=0.23$, unpaired two-tailed Student's $t$ test, $n=51$ for 3 months, 38 for $\geq 18$ months). $\boldsymbol{B}$, The distribution of total dendritic lengths in V1 does not change between 3 and 18 months ( $p=0.059$, Kolmogorov-Smirnov test, $n=51$ for 3,38 for $\geq 18$ months). C, The distribution of the number of dendritic nodes shifts toward fewer nodes between 3 and 18 months ${ }^{*} p=0.029$, Kolmogorov-Smirnov test, $n=51$ for 3,38 for $\geq 18$ months). Each $n$ represents one cell for all panels in this figure. Error bars represent SEM.

visual cortex remodel on a day-to-day basis (Lee et al., 2006). Remodeling interneurons in these mice represent all known interneuron subtypes residing within a "dynamic zone" corresponding to a superficial strip of extragranular L2/3 (Lee et al.,

outlined. Right, The experimental timeline. $\boldsymbol{B}$, MZP (top row) along with two-dimensiona projections of three-dimensional skeletal reconstructions (middle row) of a superficial L2/3 interneuron acquired over 2 weeks in a 6-month-old animal. Green boxes indicate a dynamic branch tip shown at high-magnification in bottom. Green arrow marks the approximate distal end of the branch tip on the first day of imaging (d0). C, MZP (top row) and two-dimensional projections of three-dimensional skeletal reconstructions (middle row) of a superficial L2/3 interneuron acquired over 2 weeks in an 18-month-old animal. Red boxes indicate a stable branch tip shown at high-magnification in bottom. Red arrow shows no change in the distal branch tip over 2 weeks of imaging. $\boldsymbol{D}$, Average cell FF (dynamic index) at different ages. Each circle represents an individual cell. Dashed line marks the experimentally determined threshold for a dynamic cell. The 3 month group has a significantly higher average $\mathrm{FF}$ than the 6 month group $\left({ }^{* *} p=0.0012\right.$, by bootstrap using Holm-Sidak's test with $\alpha=0.05$ to correct for multiple comparisons, $n=16$ for 3 and 14 for 6 months). The 6 month group is significantly different from the 18 month time point $\left({ }^{*} p=0.0229\right.$, by bootstrap using Holm-Sidak's test with $\alpha=0.05$ to correct for multiple comparisons, $n=14$ for 6 and 11 for 18 months), but does not differ from the later ages ( $p=0.0607$ for 6 vs 9 months, $p=0.0607$ for 6 vs 12 months, by bootstrap using Holm-Sidak's test with $\alpha=0.05$ to correct for multiple comparisons, $n=14$ for 6 months, 10 for 9 months, and 8 for 12 months,). Error bars represent SD of the bootstrapped population. Scale bars: $\boldsymbol{A}, 200 \mu \mathrm{m} ; \boldsymbol{B}, \boldsymbol{C}$ (on cells), $20 \mu \mathrm{m} ; \boldsymbol{B}, \boldsymbol{C}$ (on tips), $5 \mu \mathrm{m}$. 
2008), a cortical lamina known to retain a capacity for sensory map plasticity beyond development into adulthood (LeVay et al., 1980; Daw et al., 1992; Hirsch and Gilbert, 1993). The structural rearrangement of dynamic zone interneurons is a general feature of sensory cortices. It is shared across modalities and between primary and higher sensory areas (Chen et al., 2011a), thereby providing a common mechanism for experience-dependent functional plasticity in the adult neocortex. To test whether inhibitory interneuron structural plasticity mechanisms are retained during normal brain aging, we monitored dendritic arbor dynamics of superficial L2/3 interneurons in the visual cortex of adult thy1-GFP-S transgenic mice (Lee et al., 2006). Three weeks before reaching $3,6,9,12$, or 18 months of age, mice were surgically implanted with bilateral cranial windows over the visual cortices. Following 3 weeks of recovery, L2/3 interneurons in the dynamic zone (65-150 $\mu \mathrm{m}$ below the pial surface) were identified and a two-photon imaging volume encompassing the cell and its entire dendritic arbor was acquired. The same cells were imaged again 7 and $14 \mathrm{~d}$ later (Fig. $1 A$ ). Branch tips were reconstructed and monitored for length changes, which were then quantified using a FF analysis (Fig. $1 B-D$ ).

Our previous results (Lee et al., 2008) showed that at 3 months of age (young adults) every neuron within the dynamic zone shows a FF $>0.35$, indicating at least 1 dynamic branch tip (Fig. $1 D)$. When we compared previously collected 3 month data points (Lee et al., 2008; Chen et al., 2011b) to cells from older mice, we noticed a clear difference in variance between the groups $\left(F_{(4,54)}=2.859, p=0.032\right.$, Brown-Forsythe test, $n=16$ for 3 months, 14 for 6 months, 10 for 9 months, 8 for 12 months, 11 for 18 months). This change in variance was paralleled by a reduction in mean FF with age. When comparing the 3 month group to 6-month-old mice, an age considered mature but not old, we saw a sharp drop in dynamics measured as a statistically significant reduction in mean FF ( $p=0.0012$, by bootstrap; see Materials and Methods) using Holm-Sidak's test to correct for multiple comparisons, $n=16$ for 3 and 14 for 6 months), with less than half the cells retaining a $\mathrm{FF}>0.35$, the threshold for a dynamic cell. By 9 and 12 months of age the number of dynamic cells had further dropped, to the point where all cells had a FF $\sim<0.35$, so that by 9 months, the highest value was 0.353 . At 18 months, the average FF was significantly lower than at 6 months $(p=0.0229$, by bootstrap using Holm-Sidak's test to correct for multiple comparisons, $n=14$ for 6 and 11 for 18 months). These findings show a precipitous drop in the dynamic index of cortical inhibitory neurons with age, sooner than might have been anticipated based on other measures of aging. By the time mice reach an age considered mature, rather than old, remodeling of their inhibitory arbors is already significantly compromised.

\section{Age-related simplification of interneuron dendritic arbors}

We next asked whether interneuron arbors showed age-related changes in morphology. When comparing the number of dendrites in 3 month versus 18 month or older animals, we found no difference in the number of primary dendrites between these populations (Fig. $2 A ; t_{(87)}=1.215, p=0.23$, unpaired two-tailed Student's $t$ test, $n=51$ for 3 months, 38 for $\geq 18$ months). We also did not see a difference in the distribution of dendritic lengths over this time period (Fig. $2 B ; D=0.2843, p=0.059$, Kolmogorov-Smirnov test, $n=51$ for 3,38 for $\geq 18$ months). However, in the 3-18 month period we did see a shift in the distribution of the number of dendritic nodes (branch points; Fig. $2 C ; D=0.3122, p=0.029$, Kolmogorov-Smirnov test, $n=$ 51 for 3 months, 38 for $\geq 18$ months), suggesting an age- dependent reduction in arbor complexity. Our previous work has shown that in young adult mice interneuron dendritic dynamics are comprised of balanced additions and retractions (Chen et al., 2011a). The simplified arbors on interneurons in older mice suggested that at some point past 3 months and before 9 months, when most cells are stable (Fig. 1D), retractions should predominate. We therefore examined all dynamic branch tips at 3 and 6 months and classified them as extensions or retractions. At 3 months of age, the number of branch extensions and retractions was slightly shifted toward extensions ( $43.1 \%$ of all events were retractions). However, at 6 months branch retractions had grown more prevalent $(61.2 \%$ of all events were retractions), such that retractions constituted a significantly larger fraction of the total number of events at 6 months than at 3 months $(p=0.0258$, two-sided Fisher's exact test, 41 extensions and 31 retractions at 3 months, 33 extensions and 52 retractions at 6 months). The age-dependent reduction in branch dynamics, together with a shift toward increased branch retractions, explain our finding of simplified and stable interneuron arbors in older mice.

\section{Aging does not affect interneuron cell or synapse numbers or subtype representation}

To confirm that the specific age-related characteristics we find, of a simplified and stable arbor in aged mice, is general to all interneuron types and is not due to a selective retention of a particular interneuron subtype, we compared the prevalence of the four major interneuron subtypes in all layers of visual cortex at 3 and at 24 months. Immunohistochemical costaining for GABA and PV, vasointestinal peptide (VIP), somatostatin (SOM), or calretinin (CR) showed that the percentage of these different interneuron subtypes within the neocortical GABAergic population was consistent with previous results in young adult mice (Xu et al., 2006; Gonchar et al., 2007; Lee et al., 2008), and remained largely unchanged throughout a 2 year life span (Fig. $3 A ; p=$ 0.044 for SOM in layer $1, p=0.69$ for SOM in layer $5, p=0.84$ for $\mathrm{PV}$ in layer 6 , and $p>0.99$ for all other subtypes across layers, multiple two-tailed unpaired $t$ tests with Holm-Sidak's correction for multiple comparisons, $n=3-5$ mice for 3 months and 3-6 mice for 24 months). Further, at 24 months of age there was no difference in the representation of the different interneuron subtypes within the thyl-GFP labeled population compared with unlabeled interneurons in the same brains (Fig. $3 B ; p=0.95$ for PV in upper layer $2 / 3, p=0.98$ for CR in layer 1 , and $p>0.99$ for all other subtypes across layers, multiple two-tailed unpaired $t$ tests with Holm-Sidak's correction for multiple comparisons, $n=3$ mice for the GABA-positive cells and 6-8 for the thy 1 GFP-nonpyramidal cells). We also examined whether the number of excitatory or inhibitory synapses (VGLUT-positive or VGAT-positive, respectively) onto L2/3 dendrites or L5 pyramidal apical tufts changed between 3 and 18 months. Although such colocalization studies based on immunohistochemistry are not definitive due to their limited resolution and specificity, we found no evidence of changes in synapse densities onto the cells we examined (Fig. 3C-E; $C: t_{(14)}=0.4117, p=0.69$, unpaired two-tailed Student's $t$ test, $n=8 ; D: t_{(14)}=0.02314, p=0.99$, unpaired two-tailed Student's $t$ test, $n=7-9 ; E: t_{(12)}=1.473, p=$ 0.17 , unpaired two-tailed Student's $t$ test, $n=7$ ).

\section{Fluoxetine attenuates the age-related decline in interneuron complexity}

Because the antidepressant drug fluoxetine has been shown to promote interneuron branch remodeling in the visual cortex of 
A
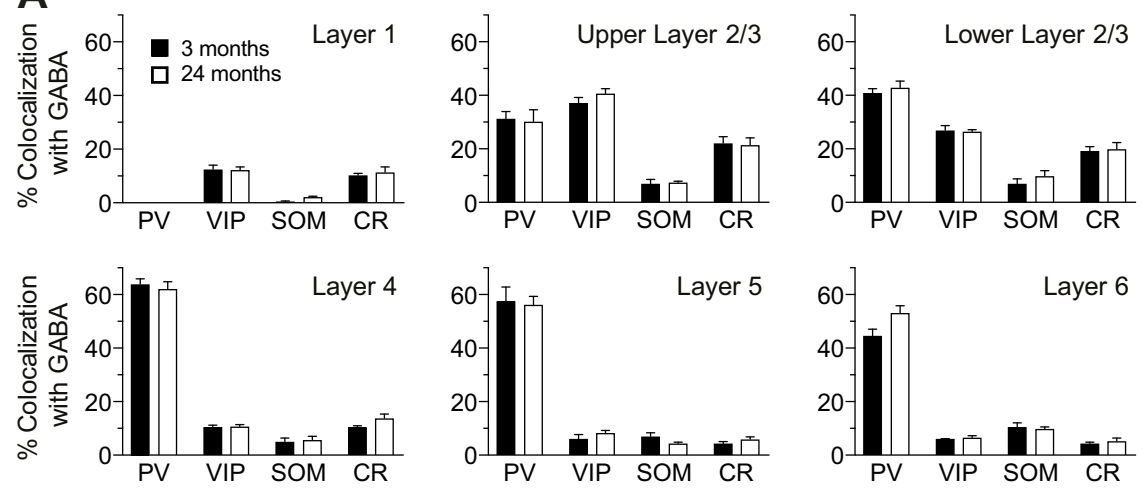

B
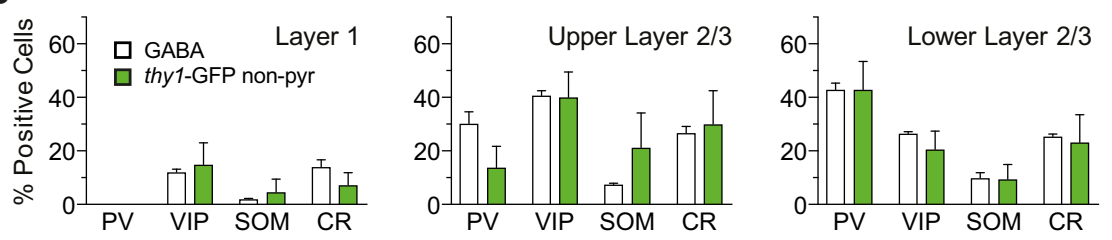

C
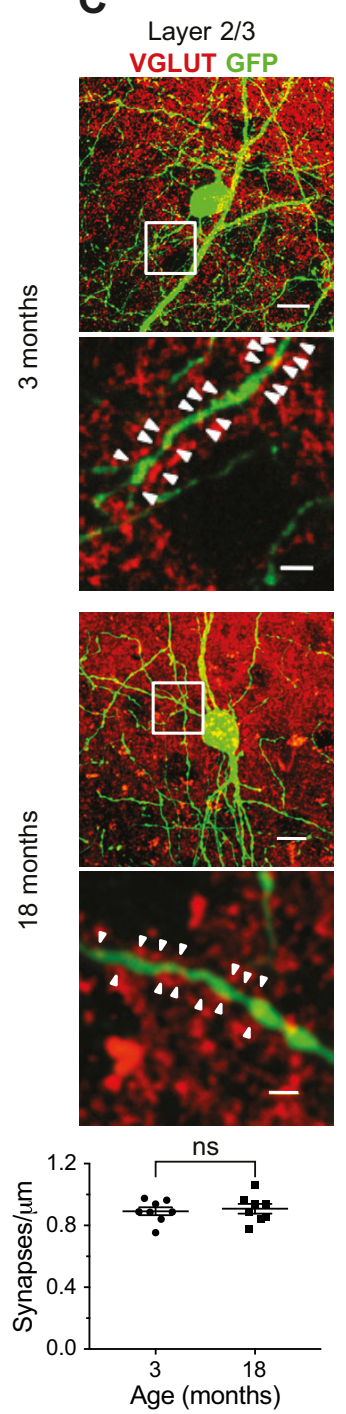

D

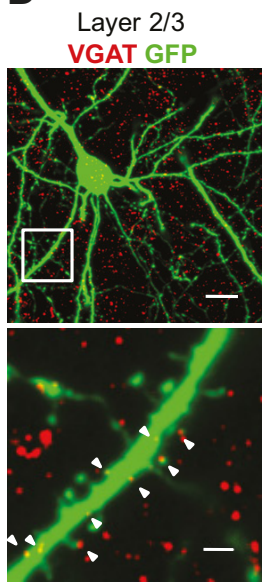

\section{E}
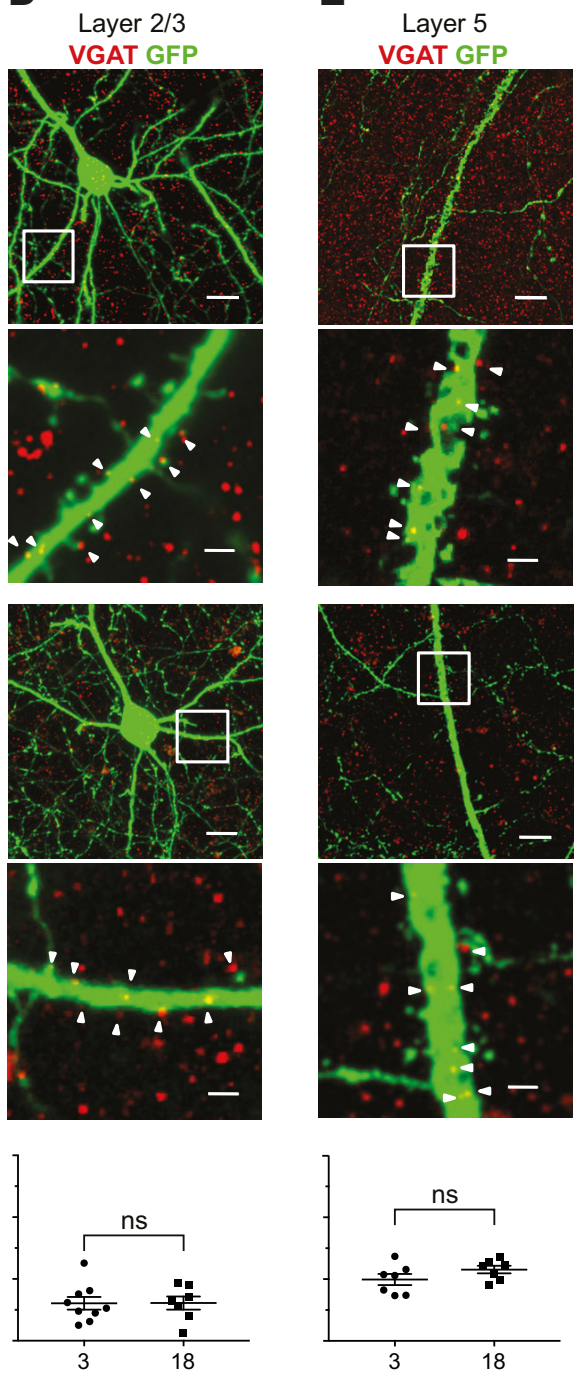

Age (months)
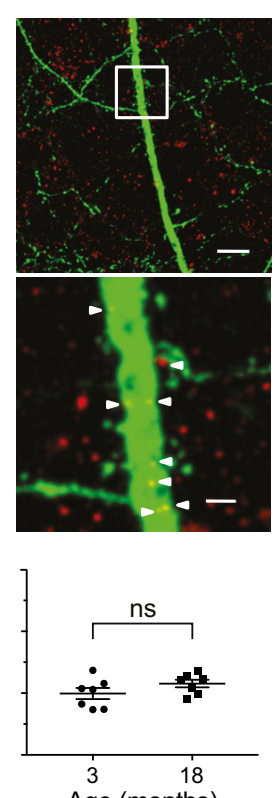

Age (months)

Figure 3. Interneuron subtype representation in layers of mouse visual cortex. $A$, Plots showing colocalization of GABA with: $P V$ VIP, SOM, and CR subtype markers in layers of visual cortex in young adult (3 months) or aged (24 months). A total of 25669 GABA-positive cells were counted. For each subtype in each layer, the percentage at 3 and 24 months was compared using a

young adult mice (Chen et al., 2011a), we asked whether it could prevent the reduced dynamics of interneuron dendritic arbors that occurs with aging. We treated animals with fluoxetine in their drinking water for 3 months starting at either 3 or 6 months of age and then compared their dynamic index to age-matched untreated controls (Fig. 4A). When mice were treated from 3 to 6 months, no effect was seen on the mean FF (Fig. $4 B ; p=0.13$, by bootstrap, $n=14$ for untreated, 8 for treated). A few of the animals at 9 months showed an improvement in FF to levels clearly above the dynamic threshold of 0.35 , resulting in a statistically significant increase in the mean FF average at this age (Fig. $4 B ; p=0.043$, by bootstrap using Holm-Sidak's test to correct for multiple comparisons, $n=10$ for untreated, 8 for treated). Given the indication that some improvement might be possible, we next tried extending the fluoxetine treatment to 6 months, starting at 3 months of age

$\leftarrow$

two-tailed Student's $t$ test. Holm-Sidak's method with $\alpha=$ 0.05 was used to correct for multiple comparisons. The relative representation of interneuron subtypes within different cortical layers was largely unchanged in aged compared with young mice $(p=0.044$ for SOM in layer $1, p=0.69$ for SOM in layer $5, p=0.84$ for PV in layer 6 , and $p>0.99$ for all other subtypes across layers, $n=3-5$ mice for 3 months and 3-6 mice for 4 months). $\boldsymbol{B}$, Interneuron subtype representation in the thy 1-GFP-labeled nonpyramidal cells in the superficial layers of visual cortex in aged mice compared with subtype representation in the GABA-positive population in the same layers. For the GABA-positive group, the same data were used as in $\boldsymbol{A}$. A total of 399 GFP nonpyramidal cells and 5262 GABApositive cells were examined. For each subtype in each layer, the percentage GABA-positive and GFP-nonpyramidal was compared using a two-tailed Student's $t$ test. Holm-Sidak's method with $\alpha=0.05$ was used to correct for multiple comparisons. Representation of the subtypes was not different between GABA-positive and GFP-nonpyramidal cells ( $p=0.95$ for $\mathrm{PV}$ in upper layer $2 / 3, p=0.98$ for $C R$ in layer 1 , and $p>$ 0.99 for all other subtypes across layers, $n=3$ mice for the GABA-positive cells and $6-8$ for the GFP-nonpyramidal cells). C, Representative images of excitatory synapses (VGLUT) on L2/3 interneuron dendrites (GFP), at 3 months (top 2 panels) and 18 months (middle 2 panels). The second and fourth panels are enlargements of the boxed regions marked in the first and third panels, respectively. Synapse densities are quantified in the bottom panel. Each data point represents one animal. There is no statistically significant difference between the two ages ( $p=0.69$, unpaired two-tailed Student's t test, $n=$ 8). D, Same as in C, except inhibitory synapses (VGAT) on L2/3 pyramidal neuron basal dendrites (GFP). There is no statistically significant difference between the two ages ( $p=0.99$, unpaired two-tailed Student's $t$ test, $n=7-9$ ). $\boldsymbol{E}$, Same as in C, except inhibitory synapses (VGAT) on L5 pyramidal neuron apical dendrites (GFP). There is no statistically significant difference between the two ages ( $p=0.17$, unpaired two-tailed Student's $t$ test, $n=7$ ). Scale bars: first and third panels, $10 \mu \mathrm{m}$; second and fourth panels, $2 \mu \mathrm{m}$. All error bars represent SEM. 
A

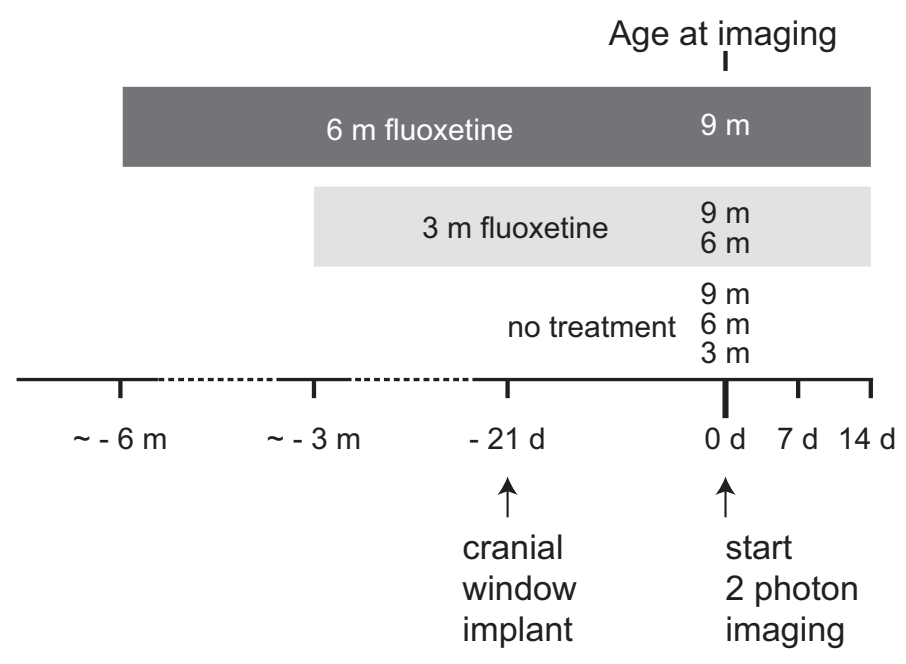

B

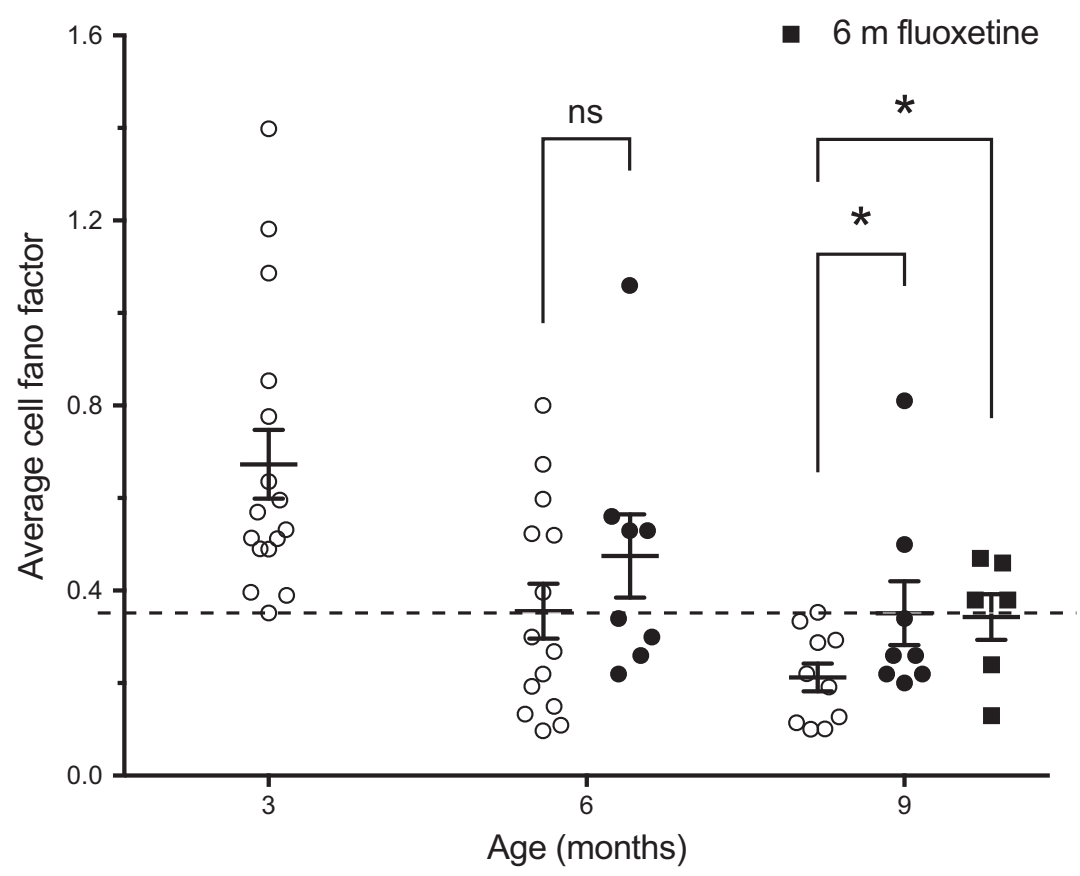

Figure 4. Fluoxetine treatment increases interneuron dynamics in aged mice. $\boldsymbol{A}$, Experimental time line. $\boldsymbol{B}$, Average cell $\mathrm{FF}$ at different ages. Each circle represents an individual cell. Dashed line marks the experimentally determined threshold ( $F F=0.35)$ for a dynamic cell. The nontreated cells are also shown in Figure 1D. Fluoxetine treatment from 3 to 6 months has no effect on the average cell FF compared with 6 month controls ( $p=0.13$, by bootstrap, $n=14$ for untreated, $n=8$ for treated). Treatment from 6 to 9 months compared with 9 month controls significantly increased the average cell FF ( ${ }^{*} p=0.043$, by bootstrap using Holm-Sidak's test with $\alpha=0.05$ to correct for multiple comparisons, $n=10$ for untreated, 8 for treated), as did treatment from 3 to 9 months ( ${ }^{*} p=0.043$, by bootstrap using Holm-Sidak's test with $\alpha=0.05$ to correct for multiple comparisons, $n=10$ for untreated, 6 for treated). However, the longer treatment resulted in FF improvement for a larger fraction of animals ( $25 \%$ for 3 months vs $67 \%$ for 6 months). Error bars represent SD of the bootstrapped population.

(Fig. 4A). Here, we found that $67 \%$ of the cells from treated animals showed dynamic arbors at 9 months of age (compared with $25 \%$ with only 3 months of treatment), again resulting in an increase in the average FF compared with untreated age-matched controls (Fig. $4 B ; p=0.043$, by bootstrap, using Holm-Sidak's test to correct for multiple comparisons, $n=10$ for untreated, 6 for treated). Although in the case of 9-month-old animals treated with fluoxetine for 3 months the statistical significance was driven by two animals with a $\mathrm{FF}>0.35$, one of which may be considered an outlier (2 SD above the mean), it is important to note that the untreated control group at 9 months does not have a single animal with a FF $>0.35$ (the highest $\mathrm{FF}=0.3531$ ). The 9 month animals with 6 months of treatment has 4 of 6 animals $>0.35$, and none of the values are even $1 \mathrm{SD}$ above the mean. The difference between 6 months of fluoxetine and no treatment is therefore robust and not driven by outliers. These data are consistent with 3 months of treatment having a variable effect on arbor plasticity (and no effect on functional plasticity, see next section), in contrast to the more penetrant effects of the 6 month treatment on both structural and functional plasticity. These results suggest that fluoxetine treatment can somewhat attenuate the age-related decline in interneuron dendrite remodeling, in particular if treatment is started early and maintained throughout the lifespan.

\section{Fluoxetine attenuates the age-related decline in visual cortex functional plasticity}

To investigate whether there is a functional correlate to the decline in interneuron structural plasticity in mouse visual cortex, we recorded VEPs and induced stimulus-selective response potentiation (SRP). This NMDA-dependent form of plasticity bears many of the hallmarks of long-term potentiation (LTP) but is induced through visual experience (Frenkel et al., 2006; Cooke and Bear, 2010). VEPs were recorded $450 \mu \mathrm{m}$ below the pia of binocular visual cortex as previously described (Frenkel and Bear, 2004) and SRP was induced through repeated presentations of sinusoidal gratings of a specific orientation. We found robust SRP in 3-month-old wild-type mice (Fig. 5A). However, levels of SRP decreased in 6month-old mice and were virtually nonexistent in 9-month-old animals (Fig. 5A; 3 months: $t_{(4)}=-5.145, p=0.0068$, paired $t$ test, $n=5$; 6 months: $t_{(9)}=$ $-5.564, p=0.00035$, paired $t$ test, $n=10$; 9 months: $t_{(4)}=-0.462, p=0.675$, paired $t$ test, $n=5$ ). To confirm that the decrease in SRP was not a result of defective vision in 9-month-olds, we assessed visual acuity and contrast sensitivity in 3-, 6-, and 9-month-old mice and found no difference between the three groups tested (Fig. 5B: $F_{(2,26)}=0.623, p=0.542$; repeated-measures MANOVA). These findings show there is a similar time course for the loss of functional plasticity in visual cortex as for the loss of interneuron structural plasticity.

In addition to promoting interneuron branch remodeling in the visual cortex of young adult mice (Chen et al., 2011a), chronic 

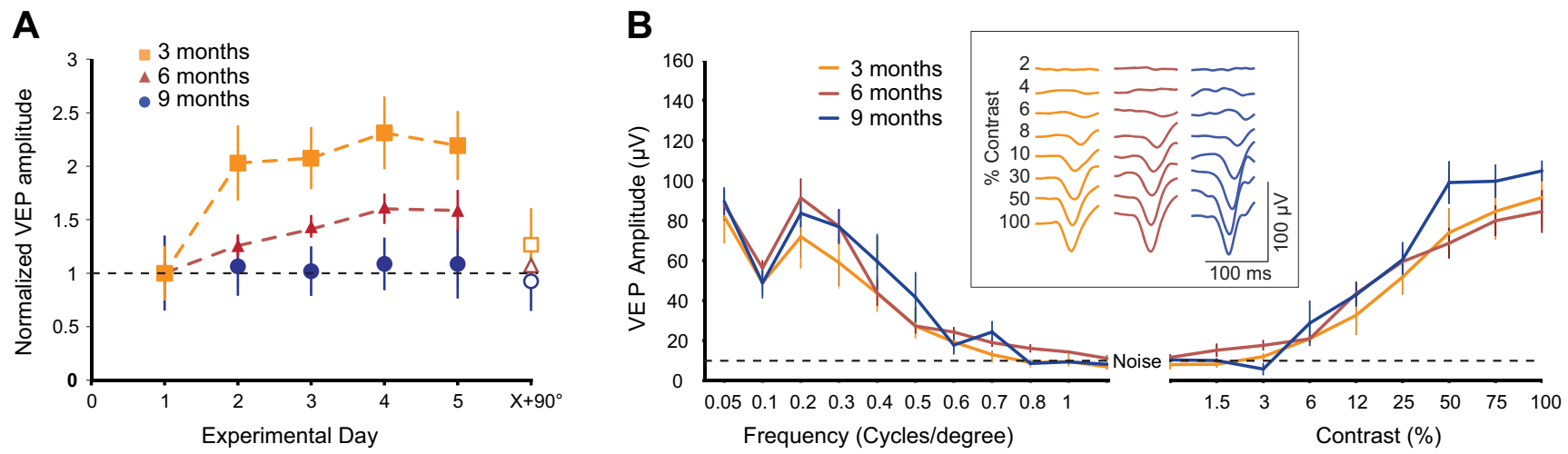

Figure 5. Stimulus response potentiation is absent in aged mice. $A$, SRP was induced in mouse visual cortex by repeated presentations of sinusoidal gratings. Three-month-old mice (orange squares) exhibited large and sustained potentiation of binocular VEPs over many days of exposure to the same stimulus orientation (Day $5=2.2 \pm 0.32$-fold increase over Day 1 ; paired $t$ test $p=$ $0.0068, n=5$ ). Six-month-old mice (red triangles) exhibited less potentiation on average per day than 3 -month-old mice but still exhibited significant SRP (Day $5=1.6 \pm 0.19$-fold increase over Day 1; paired $t$ test $p=0.00035, n=10$ ) and 9-month-old mice (blue circles) did not exhibit any statistically significant potentiation (Day $5=1.08 \pm 0.32$-fold increase over Day 1; paired $t$ test $p=0.675, n=5$ ). $\boldsymbol{B}$, Binocular VEPs were recorded at different frequencies of sinusoidal gratings or with different contrast percentages. No differences were observed between the groups $\left(F_{(2,26)}=0.623, p=0.542\right.$; repeated-measures MANOVA). Error bars represent \pm SEM. Inset, Average VEP waveforms for each age group as contrast was increased.

treatment with fluoxetine has also been show to restore juvenile levels of ocular dominance plasticity in adult mice (Maya Vetencourt et al., 2008). To test whether fluoxetine could also reverse SRP deficits in aged mice, we assessed SRP after fluoxetine treatment equivalent to that used for the structural plasticity studies (Fig. 6A). We found that 3 months of fluoxetine treatment did not improve SRP in 6- or 9-month-old mice (Fig. 6B: $t_{(14)}=$ $-1.184, p=0.256$, unpaired two-tailed Student's $t$ test, $n=6$ for treated, $n=10$ for untreated; $C: t_{(14)}=0.992, p=0.339$, unpaired two-tailed Student's $t$ test, $n=11$ for treated, $n=5$ for untreated). However, 6 months of fluoxetine treatment significantly increased SRP in 9-month-old animals (Fig. $6 C ; t_{(8)}=$ $1.996, p=0.0405$, unpaired two-tailed Student's $t$ test, $n=5$ for treated, $n=5$ for untreated). This suggests that chronic fluoxetine treatment maintains plasticity in neuronal circuits during aging, if initiated early.

\section{Discussion}

Here we examine the effects of aging on morphological and functional plasticity of inhibitory interneurons in mouse primary visual cortex (V1). We find that interneurons undergo two progressive changes with age; they become less dynamic and their dynamics shift from balanced branch additions and retractions to the prevalence of retractions over additions. Starting at 3 months of age, interneuron arbors undergo structural simplification and reduced plasticity, so that by 9 months their structure is less complex and more stable. These morphological changes run in parallel to an age-related decline in SRPs as measured by VEPs, and both can be partially prevented by long-term fluoxetine treatment.

To what extent age-related cognitive decline derives from changes to brain structure, and whether such changes are a normal part of brain aging unrelated to degenerative processes, has been hotly debated for many years. Although some longitudinal fMRI studies in human subjects suggest there is a reduction in volume of some brain areas during aging (for review, see Fjell et al., 2014a,b), the low resolution of such studies precludes an understanding of the underlying cellular basis. Loss of GABAergic neurons in aging cat striate cortex has been reported (Hua et al., 2008). Yet, overall, the evidence for neuronal loss during normal aging has not been strong (Morrison and Hof, 1997; for review, see Peters et al., 1998; Freeman et al., 2008), and we see no evi- dence of GABAergic cell loss in our studies (Fig. $3 A, B$ ). In contrast, a growing body of literature points to an age-related deterioration in neuronal connectivity (Morrison and Baxter, 2012; Dickstein et al., 2013; for review, see Hof and Morrison, 2004; Dickstein et al., 2007).

A major problem with obtaining data regarding age-related changes to neuronal numbers or structure, is that with classic anatomical methods small scale changes are difficult to detect against the enormous variance in the size and shape of individual cortical neurons. This is particularly true for inhibitory neurons, that as a group show immense morphological diversity (Kawaguchi and Kubota, 1997, 1998; Markram et al., 2004). Indeed, using conventional immunohistochemistry (Fig. 3 C) we do not see gross age-related changes in inhibitory synaptic staining. The age-related reduction in interneuron complexity we describe is discernible thanks to our ability to chronically track the same cells, visualizing their gradual simplification. Chronic in vivo two-photon imaging of dendritic spines in neocortex of up to 1 -year-old mice also suggests some age-dependent spine loss (Zuo et al., 2005; Spires-Jones et al., 2007; Mostany et al., 2013), and alterations in the size and stability of spines and boutons (Bloss et al., 2011; Mostany et al., 2013). The scale of net morphological change thus far detected by in vivo imaging in mice is overall small, and its analog in humans would be unlikely to explain large volumetric changes reported in some human fMRI studies.

Given that most branch tip dynamics are on the scale of tens of micrometers, at most, one might ask whether such changes in branch tip length represent sufficient synapse gain and loss to alter neuron and circuit function? Or in the case of brain aging, is the gradual loss of synaptic contacts due to branch tip retractions, and the eventual loss of branch dynamics, functionally meaningful? Post hoc electron microscopy (EM) reconstructions of interneuron dendrites imaged in vivo, show that new branch tips harbor synaptic contacts at a density similar to stable dendrites (Chen et al., 2011b), implying that branch tip extensions and retractions reflect synapse gain and loss, respectively. EM estimates of synaptic density on L2/3 interneuron dendrites is $\sim 1$ synapse per $\mu \mathrm{m}$ (Kubota et al., 2007). Approximately $80 \%$ of the synapses on distal interneuron dendrites represent excitatory inputs (Kubota et al., 2007) from a large number of local pyramidal 
A

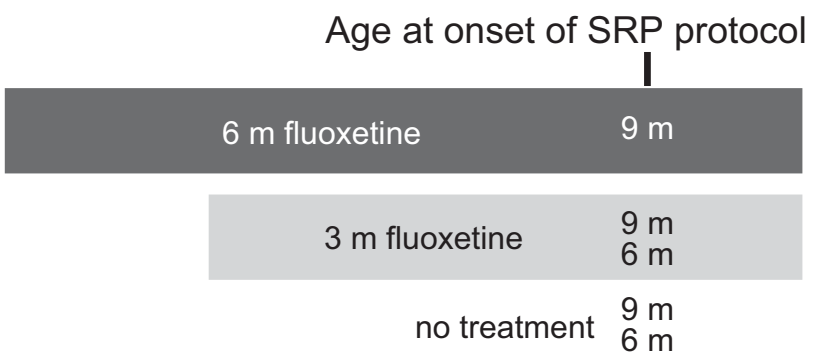

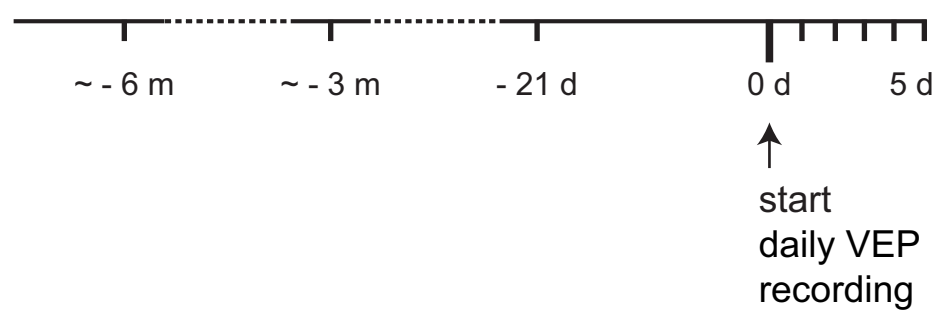

B

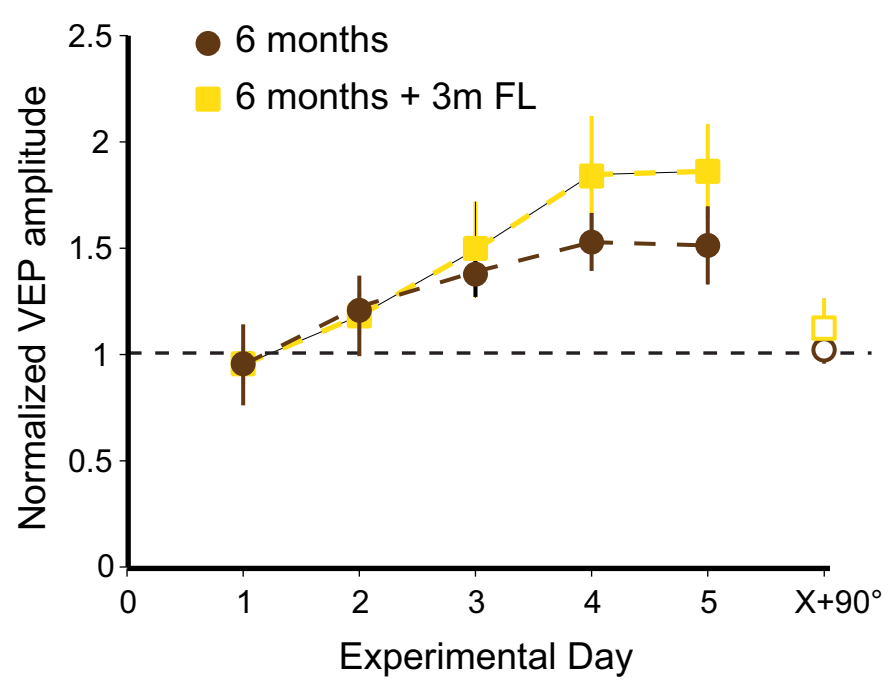

C

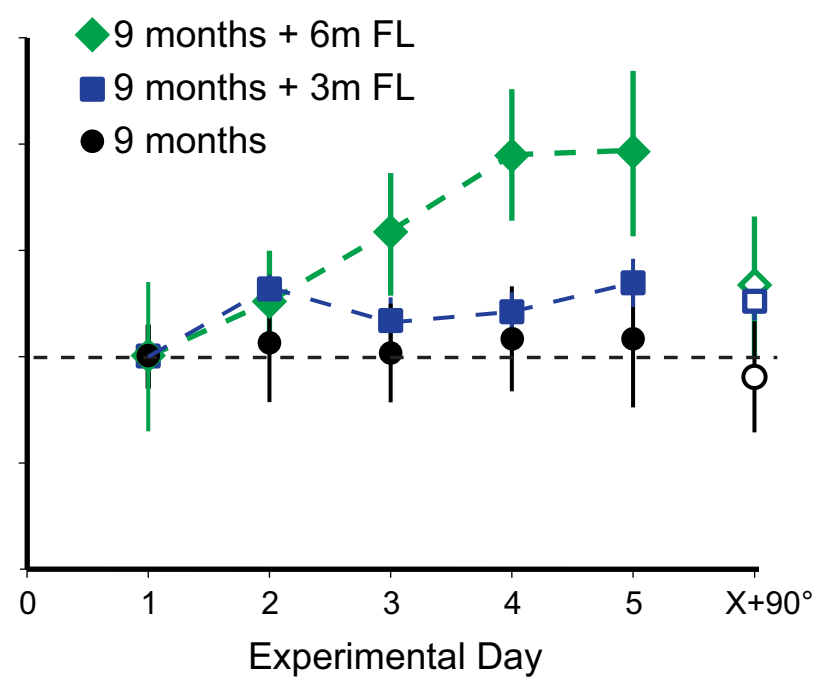

Figure 6. Chronic fluoxetine treatment of aged mice maintains stimulus response potentiation. A, Experimental time line. SRP was tested at 6 months, with or without 3 months of fluoxetine treatment, or at 9 months untreated or after 3 or 6 months of fluoxetine treatment. $\boldsymbol{B}$, Fluoxetine treatment (yellow squares) had no significant effect on SRP in 6-month-old mice measured on Day 5 (Day $5=1.95 \pm 0.23$-fold increase over Day 1; $n=6$ ) compared with untreated 6-month-old mice (brown circles; Day $5=1.6 \pm 0.19$-fold increase over Day 1; unpaired two-tailed Student's $t$ test $p=0.256, n=10$ ). C, Three months of fluoxetine treatment had no statistically significant effect on SRP in 9-month-old mice (green diamonds; Day $5=1.35 \pm 0.11$-fold increase over Day $1 ; n=11$ ) compared with untreated 9-month-old mice (black circles; Day $5=1.08 \pm 0.32$-fold increase over Day 1; t test $p=0.339, n=5$ ), but 6 months of treatment significantly increased SRP in 9-month-old (blue squares) mice compared with untreated mice (Day $5=1.95 \pm 0.39$-fold increase over Day $1 ; t$ test $p=0.0405, n=5$ ).

neurons that each contributes 3-7 synapses (Markram et al., 2004). The estimate is that as few as 10 presynaptic, temporally correlated excitatory inputs are sufficient to trigger an action potential in inhibitory cells (Buhl et al., 1997). For bitufted interneurons, a train of action potentials from even a single synaptic contact can produce an action potential (Kaiser et al., 2004). Thus, a branch tip length change of $\sim 30 \mu \mathrm{m}$ (or $\sim 30$ synapses) per cell could potentially alter the connectivity of 5-10 excitatory presynaptic partners, each with significant ability to initiate interneuron firing.

Further, structural remodeling in the adult brain has been proposed as a means to increase spatial access to potential synaptic contacts (Chklovskii et al., 2004). The geometry and space occupied by a dendritic spine in mouse cortex renders it capable of making $\sim 4$ potential synaptic contacts (Stepanyants et al., 2002). An entire dendritic branch tip likely contains an even higher number of possible synaptic connections considering its size in relation to a dendritic spine. Increasing an interneuron's potential for sampling distinct circuits would be most readily achieved by modest length changes in several branch tips spatially distributed throughout the dendritic field compared with a substantial length change of a single branch tip. The cell type and laminar-specificity of dendritic structural dynamics (Chen et al., 2011a,b) argue that partner sampling that occurs during synaptic remodeling is circuit specific. Thus, it may not be the net number of synapses lost during aging that matters to a given neuron, but rather its reduced connectivity with specific neuronal partners within the local circuit, and the inability to trade or shuffle remaining partners.

Perhaps due to the fact that the overwhelming majority of synapses in the neocortex are excitatory, prior ex vivo postmortem as well as newer imaging studies have mostly focused on dendritic spines on excitatory pyramidal neurons. Yet, inhibitory neurons play an important role in modulating excitatory 
neuron function and plasticity within the cortical circuit (for review, see Singer, 1996; McBain and Fisahn, 2001; Dan and Poo, 2004; Foeller and Feldman, 2004) and have also been implicated in sensory map plasticity in the adult neocortex (Jacobs and Donoghue, 1991; Jones, 1993). Further, age-related deterioration of visual function in nonhuman primates, manifested as increased responsiveness to all orientations and directions as well as an increase in spontaneous activity, is consistent with a decline in intracortical inhibition (Schmolesky et al., 2000).

We have previously shown interneuron dendritic remodeling in superficial L2/3 of primary visual cortex (Lee et al., 2008), which is experience-dependent (Chen et al., 2011b), and seems to be a general feature of the adult cortical microcircuit across different sensory modalities and primary versus higher-order sensory regions (Chen et al., 2011a). Here we show that inhibitory neuron remodeling declines with age with a time course that mirrors the decline in visual cortex plasticity. These findings are in line with functional data suggesting that deficits in inhibitory circuit function contribute to age-related impairments in visual perception (Schmolesky et al., 2000; Leventhal et al., 2003) and perhaps more broadly to sensory, motor, and cognitive tasks that rely on the neocortex.

Given that interneuron remodeling in superficial $\mathrm{L} 2 / 3$ is not restricted to specific interneuron subtypes (Lee et al., 2008) and imaged neurons are sampled randomly, the finding that at 3 months every imaged interneuron is dynamic ( FF $>0.35)$, and at 9 months none are dynamic $(\mathrm{FF}<0.35)$, suggest that the general phenomenon of reduced dynamics with age, is unlikely to be subtype specific. It could be that some subtypes are affected earlier than others. However, a much larger sample size would be required to discern such an effect.

During development, the functional maturation of inhibitory circuits is thought to trigger the onset and closure of the critical period for OD plasticity in V1 (Jiang et al., 2005; Levelt and Hübener, 2012; for review, see Hensch, 2004, 2005;). Increasing cortical inhibition, for example with the GABA agonist benzodiazepam, can induce a precocious critical period (Fagiolini and Hensch, 2000). Conversely, treatments that limit inhibition in the adult, such as injection of the GABA(A) antagonist bicuculline (Duffy et al., 1976; Sillito et al., 1981), or treatment with the antidepressant fluoxetine (Sale et al., 2007; Maya Vetencourt et al., 2008; Harauzov et al., 2010), can restore juvenile plasticity. Fluoxetine treatment during normal vision enhances structural dynamics of cortical interneurons, and during MD provides a permissive environment that facilitates OD plasticity (Chen et al., 2011b). Here we show that fluoxetine can also ameliorate the age-related decline in structural and functional plasticity of visual cortex neurons. Longer treatment time improved outcome, which could be because of the more prolonged treatment duration, or alternatively, to the earlier intervention. Although there was a measurable and significant improvement in the fluoxetinetreated older animal groups, it is interesting to note that not all animals showed improvement, suggesting that therapeutic intervention may be an avenue for reducing age-related neuronal deficits, but potentially not in all individuals. Clinical trials testing treatment with fluoxetine for patients with mild cognitive impairment, show improvement in the Mini-Mental Status Examination not seen in the placebo group (Mowla et al., 2007). This preliminary study needs to be confirmed in larger double-blind placebo-controlled cohorts. It would be interesting to note in this case too, if there is interpatient variability in response, as well as an efficacy dependence on treatment duration or time of intervention.

The traditional form of OD plasticity induced by MD in adult animals seems to be lost with aging (Lehmann and Löwel, 2008). However, some forms of experience-dependent plasticity persist in adults (Sawtell et al., 2003; Frenkel et al., 2006), and much less is known regarding how these are affected by inhibition and modulatory systems across the lifespan. SRP is particularly robust in juvenile mice (Schecter et al., 2017), but can still be induced reliably in adults. Induction of SRP appears to share many features with the phenomenon of LTP (Cooke and Bear, 2010), and the expression of this plasticity is highly dependent upon intact cortical inhibition (Kaplan et al., 2016). Thus, it was of considerable interest to understand how this type of plasticity changes at ages when GABAergic neurons become structurally stable. Although we cannot ascribe a causal role of age-related changes in interneurons to the dramatic decline in SRP, it is particularly interesting that chronic treatment with fluoxetine, which partially restored malleability to interneurons in old age, also restored juvenile levels of SRP. Our finding that fluoxetine treatment in aging mice can attenuate the concurrent age-related declines in interneuron structural and visual cortex functional plasticity suggests it could provide an important therapeutic approach toward mitigation of sensory and cognitive deficits associated with aging, provided it is initiated before severe network deterioration.

\section{References}

Andersen GJ (2012) Aging and vision: changes in function and performance from optics to perception. Wiley Interdiscip Rev Cogn Sci 3:403-410. CrossRef Medline

Anderson B, Rutledge V (1996) Age and hemisphere effects on dendritic structure. Brain 119:1983-1990. CrossRef Medline

Bloss EB, Janssen WG, Ohm DT, Yuk FJ, Wadsworth S, Saardi KM, McEwen BS, Morrison JH (2011) Evidence for reduced experience-dependent dendritic spine plasticity in the aging prefrontal cortex. J Neurosci 31: 7831-7839. CrossRef Medline

Buhl EH, Tamás G, Szilágyi T, Stricker C, Paulsen O, Somogyi P (1997) Effect, number and location of synapses made by single pyramidal cells onto aspiny interneurones of cat visual cortex. J Physiol 500:689-713. CrossRef Medline

Chattopadhyaya B, Di Cristo G, Higashiyama H, Knott GW, Kuhlman SJ, Welker E, Huang ZJ (2004) Experience and activity-dependent maturation of perisomatic GABAergic innervation in primary visual cortex during a postnatal critical period. J Neurosci 24:9598-9611. CrossRef Medline

Chen JL, Nedivi E (2013) Highly specific structural plasticity of inhibitory circuits in the adult neocortex. Neuroscientist 19:384-393. CrossRef Medline

Chen JL, Flanders GH, Lee WC, Lin WC, Nedivi E (2011a) Inhibitory dendrite dynamics as a general feature of the adult cortical microcircuit. J Neurosci 31:12437-12443. CrossRef Medline

Chen JL, Lin WC, Cha JW, So PT, Kubota Y, Nedivi E (2011b) Structural basis for the role of inhibition in facilitating adult brain plasticity. Nat Neurosci 14:587-594. CrossRef Medline

Chklovskii DB, Mel BW, Svoboda K (2004) Cortical rewiring and information storage. Nature 431:782-788. CrossRef Medline

Cooke SF, Bear MF (2010) Visual experience induces long-term potentiation in the primary visual cortex. J Neurosci 30:16304-16313. CrossRef Medline

Cooke SF, Komorowski RW, Kaplan ES, Gavornik JP, Bear MF (2015) Visual recognition memory, manifested as long-term habituation, requires synaptic plasticity in V1. Nat Neurosci 18:262-271. CrossRef Medline

Dan Y, Poo MM (2004) Spike timing-dependent plasticity of neural circuits. Neuron 44:23-30. CrossRef Medline

Daw NW, Fox K, Sato H, Czepita D (1992) Critical period for monocular deprivation in the cat visual cortex. J Neurophysiol 67:197-202. CrossRef Medline 
Dickstein DL, Kabaso D, Rocher AB, Luebke JI, Wearne SL, Hof PR (2007) Changes in the structural complexity of the aged brain. Aging Cell 6:275284. CrossRef Medline

Dickstein DL, Weaver CM, Luebke JI, Hof PR (2013) Dendritic spine changes associated with normal aging. Neuroscience 251:21-32. CrossRef Medline

Duffy FH, Burchfiel JL, Conway JL (1976) Bicuculline reversal of deprivation amblyopia in the cat. Nature 260:256-257. CrossRef Medline

Fagiolini M, Hensch TK (2000) Inhibitory threshold for critical-period activation in primary visual cortex. Nature 404:183-186. CrossRef Medline

Fernandez F, Garner CC (2007) Over-inhibition: a model for developmental intellectual disability. Trends Neurosci 30:497-503. CrossRef Medline

Fjell AM, McEvoy L, Holland D, Dale AM, Walhovd KB, Walhovd KB; Alzheimer's Disease Neuroimaging Initiative (2014a) What is normal in normal aging? Effects of aging, amyloid and Alzheimer's disease on the cerebral cortex and the hippocampus. Prog Neurobiol 117, 20-40. CrossRef Medline

Fjell AM, Westlye LT, Grydeland H, Amlien I, Espeseth T, Reinvang I, Raz N, Dale AM, Walhovd KB; Alzheimer Disease Neuroimaging Initiative (2014b) Accelerating cortical thinning: unique to dementia or universal in aging? Cereb Cortex 24, 919-934. CrossRef Medline

Foeller E, Feldman DE (2004) Synaptic basis for developmental plasticity in somatosensory cortex. Curr Opin Neurobiol 14:89-95. CrossRef Medline

Freeman SH, Kandel R, Cruz L, Rozkalne A, Newell K, Frosch MP, HedleyWhyte ET, Locascio JJ, Lipsitz LA, Hyman BT (2008) Preservation of neuronal number despite age-related cortical brain atrophy in elderly subjects without Alzheimer disease. J Neuropathol Exp Neurol 67:12051212. CrossRef Medline

Frenkel MY, Bear MF (2004) How monocular deprivation shifts ocular dominance in visual cortex of young mice. Neuron 44:917-923. CrossRef Medline

Frenkel MY, Sawtell NB, Diogo AC, Yoon B, Neve RL, Bear MF (2006) Instructive effect of visual experience in mouse visual cortex. Neuron 51:339-349. CrossRef Medline

Gallo JJ, Lebowitz BD (1999) The epidemiology of common late-life mental disorders in the community: themes for the new century. Psychiatr Serv 50:1158-1166. CrossRef Medline

Gonchar Y, Wang Q, Burkhalter A (2007) Multiple distinct subtypes of GABAergic neurons in mouse visual cortex identified by triple immunostaining. Front Neuroanat 1:3. CrossRef Medline

Grill JD, Riddle DR (2002) Age-related and laminar-specific dendritic changes in the medial frontal cortex of the rat. Brain Res 937:8-21. CrossRef Medline

Harauzov A, Spolidoro M, DiCristo G, De Pasquale R, Cancedda L, Pizzorusso T, Viegi A, Berardi N, Maffei L (2010) Reducing intracortical inhibition in the adult visual cortex promotes ocular dominance plasticity. J Neurosci 30:361-371. CrossRef Medline

Hebert LE, Weuve J, Scherr PA, Evans DA (2013) Alzheimer disease in the United States (2010-2050) estimated using the 2010 census. Neurology 80:1778-1783. CrossRef Medline

Hensch TK (2004) Critical period regulation. Annu Rev Neurosci 27:549579. CrossRef Medline

Hensch TK (2005) Critical period mechanisms in developing visual cortex. Curr Top Dev Biol 69:215-237. CrossRef Medline

Hickmott P, Dinse H (2013) Effects of aging on properties of the local circuit in rat primary somatosensory cortex (S1) in vitro. Cereb Cortex 23: 2500-2513. CrossRef Medline

Hirsch JA, Gilbert CD (1993) Long-term changes in synaptic strength along specific intrinsic pathways in the cat visual cortex. J Physiol 461:247-262. CrossRef Medline

Hof PR, Morrison JH (2004) The aging brain: morphomolecular senescence of cortical circuits. Trends Neurosci 27:607-613. CrossRef Medline

Hua T, Kao C, Sun Q, Li X, Zhou Y (2008) Decreased proportion of GABA neurons accompanies age-related degradation of neuronal function in cat striate cortex. Brain Res Bull 75:119-125. CrossRef Medline

Jacobs B, Scheibel AB (1993) A quantitative dendritic analysis of Wernicke's area in humans: I. Lifespan changes. J Comp Neurol 327:83-96. CrossRef Medline

Jacobs KM, Donoghue JP (1991) Reshaping the cortical motor map by unmasking latent intracortical connections. Science 251:944-947. CrossRef Medline

Jiang B, Huang ZJ, Morales B, Kirkwood A (2005) Maturation of GABAer- gic transmission and the timing of plasticity in visual cortex. Brain Res Brain Res Rev 50:126-133. CrossRef Medline

Jones EG (1993) GABAergic neurons and their role in cortical plasticity in primates. Cereb Cortex 3:361-372. CrossRef Medline

Kaiser KM, Lübke J, Zilberter Y, Sakmann B (2004) Postsynaptic calcium influx at single synaptic contacts between pyramidal neurons and bitufted interneurons in layer $2 / 3$ of rat neocortex is enhanced by backpropagating action potentials. J Neurosci 24:1319-1329. CrossRef Medline

Kalisch T, Ragert P, Schwenkreis P, Dinse HR, Tegenthoff M (2009) Impaired tactile acuity in old age is accompanied by enlarged hand representations in somatosensory cortex. Cereb Cortex 19:1530-1538. CrossRef Medline

Kaplan ES, Cooke SF, Komorowski RW, Chubykin AA, Thomazeau A, Khibnik LA, Gavornik JP, Bear MF (2016) Contrasting roles for parvalbumin-expressing inhibitory neurons in two forms of adult visual cortical plasticity. eLife 5:e11450. CrossRef Medline

Kawaguchi S, Kishikawa M, Sakae M, Nakane Y (1995) Age-related changes in basal dendrite and dendritic spine of hippocampal pyramidal neurons (CA1) among SAMP1TA/Ngs-quantitative analysis by the rapid golgi method. Mech Ageing Dev 83:11-20. CrossRef Medline

Kawaguchi Y, Kubota Y (1997) GABAergic cell subtypes and their synaptic connections in rat frontal cortex. Cereb Cortex 7:476-486. CrossRef Medline

Kawaguchi Y, Kubota Y (1998) Neurochemical features and synaptic connections of large physiologically-identified GABAergic cells in the rat frontal cortex. Neuroscience 85:677-701. CrossRef Medline

Kirova AM, Bays RB, Lagalwar S (2015) Working memory and executive function decline across normal aging, mild cognitive impairment, and Alzheimer's disease. Biomed Res Int 2015:748212. CrossRef Medline

Kubota Y, Karube G, Sekigawa A, Nomura M, Aoyagi T, Mochizuki Y, Kawaguchi Y (2007) Dendritic dimensions of cortical nonpyramidal cells. Soc Neurosci Abstr 58:S73

Kuhn HG, Dickinson-Anson H, Gage FH (1996) Neurogenesis in the dentate gyrus of the adult rat: age-related decrease of neuronal progenitor proliferation. J Neurosci 16:2027-2033. CrossRef Medline

Lee WC, Huang H, Feng G, Sanes JR, Brown EN, So PT, Nedivi E (2006) Dynamic remodeling of dendritic arbors in GABAergic interneurons of adult visual cortex. PLoS Biol 4:e29. Medline

Lee WC, Chen JL, Huang H, Leslie JH, Amitai Y, So PT, Nedivi E (2008) A dynamic zone defines interneuron remodeling in the adult neocortex. Proc Natl Acad Sci U S A 105:19968-19973. CrossRef Medline

Lehmann K, Löwel S (2008) Age-dependent ocular dominance plasticity in adult mice. PLoS One 3:e3120. CrossRef Medline

LeVay S, Wiesel TN, Hubel DH (1980) The development of ocular dominance columns in normal and visually deprived monkeys. J Comp Neurol 191:1-51. CrossRef Medline

Levelt CN, Hübener M (2012) Critical-period plasticity in the visual cortex. Annu Rev Neurosci 35:309-330. CrossRef Medline

Leventhal AG, Wang Y, Pu M, Zhou Y, Ma Y (2003) GABA and its agonists improved visual cortical function in senescent monkeys. Science 300:812-815. CrossRef Medline

Markram H, Toledo-Rodriguez M, Wang Y, Gupta A, Silberberg G, Wu C (2004) Interneurons of the neocortical inhibitory system. Nat Rev Neurosci 5:793-807. CrossRef Medline

Masliah E, Mallory M, Hansen L, DeTeresa R, Terry RD (1993) Quantitative synaptic alterations in the human neocortex during normal aging. Neurology 43:192-197. CrossRef Medline

Maya Vetencourt JF, Sale A, Viegi A, Baroncelli L, De Pasquale R, O’Leary OF, Castrén E, Maffei L (2008) The antidepressant fluoxetine restores plasticity in the adult visual cortex. Science 320:385-388. CrossRef Medline

McBain CJ, Fisahn A (2001) Interneurons unbound. Nat Rev Neurosci 2:11-23. CrossRef Medline

Morrison JH, Baxter MG (2012) The ageing cortical synapse: hallmarks and implications for cognitive decline. Nat Rev Neurosci 13:240-250. CrossRef Medline

Morrison JH, Hof PR (1997) Life and death of neurons in the aging brain. Science 278:412-419. CrossRef Medline

Mostany R, Anstey JE, Crump KL, Maco B, Knott G, Portera-Cailliau C 
(2013) Altered synaptic dynamics during normal brain aging. J Neurosci 33:4094-4104. CrossRef Medline

Mowla A, Mosavinasab M, Pani A (2007) Does fluoxetine have any effect on the cognition of patients with mild cognitive impairment? A doubleblind, placebo-controlled, clinical trial. J Clin Psychopharmacol 27:6770. CrossRef Medline

Ou X, Buckwalter G, McNeill TH, Walsh JP (1997) Age-related change in short-term synaptic plasticity intrinsic to excitatory striatal synapses. Synapse 27:57-68. CrossRef Medline

Peters A, Morrison JH, Rosene DL, Hyman BT (1998) Feature article: are neurons lost from the primate cerebral cortex during normal aging? Cereb Cortex 8:295-300. CrossRef Medline

Petersen RC, Lopez O, Armstrong MJ, Getchius TSD, Ganguli M, Gloss D, Gronseth GS, Marson D, Pringsheim T, Day GS, Sager M, Stevens J, Rae-Grant A (2018) Practice guideline update summary: mild cognitive impairment: report of the guideline development, dissemination, and implementation subcommittee of the am academy of neurology. Neurology 90:126-135. CrossRef Medline

Sale A, Maya Vetencourt JF, Medini P, Cenni MC, Baroncelli L, De Pasquale R, Maffei L (2007) Environmental enrichment in adulthood promotes amblyopia recovery through a reduction of intracortical inhibition. Nat Neurosci 10:679-681. CrossRef Medline

Sale A, Berardi N, Spolidoro M, Baroncelli L, Maffei L (2010) GABAergic inhibition in visual cortical plasticity. Front Cell Neurosci 4:10. CrossRef Medline

Sawtell NB, Frenkel MY, Philpot BD, Nakazawa K, Tonegawa S, Bear MF (2003) NMDA receptor-dependent ocular dominance plasticity in adult visual cortex. Neuron 38:977-985. CrossRef Medline

Schecter RW, Maher EE, Welsh CA, Stevens B, Erisir A, Bear MF (2017) Experience-dependent synaptic plasticity in V1 occurs without microglial CX3CR1. J Neurosci 37:10541-10553. CrossRef Medline

Schmolesky MT, Wang Y, Pu M, Leventhal AG (2000) Degradation of stim- ulus selectivity of visual cortical cells in senescent rhesus monkeys. Nat Neurosci 3:384-390. CrossRef Medline

Shankar S, Teyler TJ, Robbins N (1998) Aging differentially alters forms of long-term potentiation in rat hippocampal area CA1. J Neurophysiol 79:334-341. CrossRef Medline

Sillito AM, Kemp JA, Blakemore C (1981) The role of GABAergic inhibition in the cortical effects of monocular deprivation. Nature 291:318-320. CrossRef Medline

Singer W (1996) Neurophysiology: the changing face of inhibition. Curr Biol 6:395-397. CrossRef Medline

Spires-Jones TL, Meyer-Luehmann M, Osetek JD, Jones PB, Stern EA, Bacskai BJ, Hyman BT (2007) Impaired spine stability underlies plaquerelated spine loss in an Alzheimer's disease mouse model. Am J Pathol 171:1304-1311. CrossRef Medline

Stepanyants A, Hof PR, Chklovskii DB (2002) Geometry and structural plasticity of synaptic connectivity. Neuron 34:275-288. CrossRef Medline

Wu YT, Fratiglioni L, Matthews FE, Lobo A, Breteler MM, Skoog I, Brayne C (2016) Dementia in Western europe: epidemiological evidence and implications for policy making. Lancet Neurol 15:116-124. CrossRef Medline

Xu HT, Pan F, Yang G, Gan WB (2007) Choice of cranial window type for in vivo imaging affects dendritic spine turnover in the cortex. Nat Neurosci 10:549-551. CrossRef Medline

Xu X, Roby KD, Callaway EM (2006) Mouse cortical inhibitory neuron type that coexpresses somatostatin and calretinin. J Comp Neurol 499:144160. CrossRef Medline

Zec RF (1995) The neuropsychology of aging. Exp Gerontol 30:431-442. CrossRef Medline

Zuo Y, Lin A, Chang P, Gan WB (2005) Development of long-term dendritic spine stability in diverse regions of cerebral cortex. Neuron 46:181189. CrossRef Medline 